\title{
THE EYE-PIGMENTARY SYSTEM OF DROSOPHILA
}

\author{
VIII. SERIES OF MULTIPLE ALLELES
}

\author{
D. J. NOLTE \\ Department of Zoology, University of the Witwotersrand
}

Received 3.vi. 58

THE study of multiple alleles at a locus is of prime importance for research on the theory of the gene-its qualitative and quantitative effects and the relationship between function and mutation. In an effort to obtain data of this nature in regard to the process of eye pigmentation in Drosophila melanogaster nine series of multiple alleles, that is, at the loci of scarlet, vermilion, cinnabar, brown, pink, carnation, garnet, raspberry and prune, were investigated for the histology of the four eye-pigment regions and the spectrophotometric properties of the red and brown pigments. These methods have been fully described (Nolte, 1952, 1954). These multiple alleles consisted of the following :- - scarlet $(s t)$ and scarlet-spotted $\left(s t^{s p}\right)$; vermilion $(v)$ and vermilion ${ }^{36 f}\left(v^{36 f}\right)$; cinnabar $(c n)$ and cinnabar ${ }^{35 k}\left(c n^{35 k}\right)$; brown $(b w)$, brown ${ }^{2 b}\left(b w^{2 b}\right)$, brown-dominant $\left(b w^{D}\right)$ and brown ${ }^{4}\left(b w^{4}\right)$; pink $(p)$ and pink-peach $\left(p^{p}\right)$; carnation $(c a r)$ and carnation ${ }^{2}\left(c a r^{2}\right)$; garnet $(g)$, garnet ${ }^{2}\left(g^{2}\right)$, garnet ${ }^{3}\left(g^{3}\right)$ and garnet ${ }^{4}\left(g^{4}\right)$; raspberry (ras), raspberry $^{2}\left(\operatorname{ras}^{2}\right)$ and raspberry ${ }^{3}\left(\operatorname{ras}^{3}\right)$; prune $(p n)$ and $\operatorname{prune}^{2}\left(p n^{2}\right)$.

\section{OBSERVATIONS}

\section{(i) Phenotype}

The macroscopic phenotypes of some of these alleles, in the stocks maintained in this laboratory, differ somewhat from the descriptions as given by Bridges and Brehme (1944), as will duly be noted. The eye-colour of $s t^{s p}$ is very like that of the wild-type, with perhaps a pitted effect, i.e., small dark spots, but is not speckled; the combination $s t^{s p} / s t$ is bright red and not speckled. The eye colour of $v^{36 f}$ is a softer bright red than that of $v$, and of $c n^{35 k}$ is a darker red than that of $c n$; the combination $c n^{35 k} / c n$ is bright red. The alleles $b w, b w^{2 b}$ and $b w^{D}$ have a translucent garnet eye-colour, with that of $b w^{2 b}$ more reddish than that of $b w$ and that of $b w^{D}$ more purplish or darker; the allele $b w^{4}$ is wild-type in phenotype, and in the combination $b w w^{4} / b w$ the colour is not a darker brown but resembles that of the wild-type although it looks somewhat darker than normal. The allele $p^{p}$ has an eye colour, after ageing, which is more a brownish-ruby than the dull purplish-ruby of $p$. The two alleles $c a r$ and $c a r^{2}$ have very similar eye colours, of the dark ruby or garnct type. In the garnet series the alleles $g$ and $g^{3}$ are very alike, having a deep ruby or garnet eye colour, while $g^{2}$ and $g^{4}$ are alike in having a more translucent ruby eye colour, with the latter perhaps slightly the lighter. 
The eyes of ras are darker than the dark translucent ruby or garnet of $r^{2}$, while for $\operatorname{ras}^{3}$ the cye colour of the female is wild type and of the male a translucent maroon darkcning to wild type within a day or two after emergence. The allele $p n^{2}$ has ruby eyes, lighter than the dark brown-purplish garnct of $p n$.

\section{(ii) Histology}

The histological pictures of each series of multiple alleles will be compared with that of the alleles already described in previous studies. Sections of the eyes of $s t^{s p}$ resemble those of $s t$ excepting that the larger-sized granulcs of st were not observed (Nolte, I950); no definite evidence of variegation (or absence of pigment in parts of the ommatidia) was found. Histologically the eyes of $v^{36 f}$ resemble those of $v$, and of $c n^{35^{k}}$ those of $c n$; it appears as if the basal pigment cells of these four mutants are smaller than they are in the wild-type. The allele $b w^{2 b}$ has a coloration in the four pigment regions similar to that described for bw (Nolte, I950), but for $b w^{D}$ the colour of all pigment granules is a darker brown, with the secondary and postretinal pigment regions brown and not purplish-brown as in the other two alleles, while the rhabdomes seem to be coloured yellow; in all three alleles some large granules appear in the primary pigment cells. The allele $b w w^{4}$ resembles wild-typc in cyc histology, and so does the combination $b w^{4} / b w$. Whereas all four pigment regions in the mutant $p$ are brown in colour, in the allele $p^{p}$, although the general colour tone is lighter, the basal and post-retinal regions look darker than the distal regions; in both alleles some granules larger than normal occur in the secondary pigment cells. The alleles car and $c a r^{2}$ are similar in the coloration of the various pigment regions and both possess the very small basal pigment ccll-masses (Nolte, r950). In the garnet series the allele $g$ resembles $g^{3}$ (Nolte, I 950) in its eye histology, although in the primary cells $g^{3}$ has larger and darker brown granules while in $g$ this region resembles the other thrce regions in colour tone and granule size. The alleles $g^{2}$ and $g^{4}$ present a picture similar to that of $g^{3}$ excepting that they are lighter in colour. In the raspberry series the allele ras resembles ras (Nolte, I950), although in ras the brown granulcs of the primary pigment cells seem more yellowish in aggregate and this colour extends into the distal parts of the secondary cells. In ras the secondary pigment cells are less disrupted than in ras $^{2}$, the rounded masscs being much less in number. More often these cells (or their pigmented granules) show a stringy appcarance in ras, this bcing corrclated with the more regular orientation of the basal pigment cells. The allelc ras $^{3}$ has, in both sexes, cycs which appear to be typically wild-type in histological structure and colour tone. The allele $p n^{2}$ rescmbles $p n$ in the disrupted appearance of the secondary pigment cell region (Nolte, 1955) and the irregularity in number and orientation of the basal pigment cells, but the colour is a much lighter brown. 
(iii) Photometric analysis

The red and brown pigments extracted from the eyes of all these mutants by the AEA and AMA solvents respectively are typical of those of the wild-type, with the exception of the AEA extract of ras and $\mathrm{ras}^{2}$. In these alleles light absorption in the ultra-violet range is modified as is seen in fig. I, in which the spectrophotometric curves of the AEA extract are compared with that of $p n$ which is of the normal type. The data for the quantitative determinations of the red and brown pigments were obtained for IO-I 2 cultures of each strain and are given in the table, the measurements being that of extinction $(E)$ at $480 \mathrm{~m} \mu$ for the red pigment and at $444 \mathrm{~m} \mu$ for the brown pigment, for concentrations of io heads per I c.c. solvent.

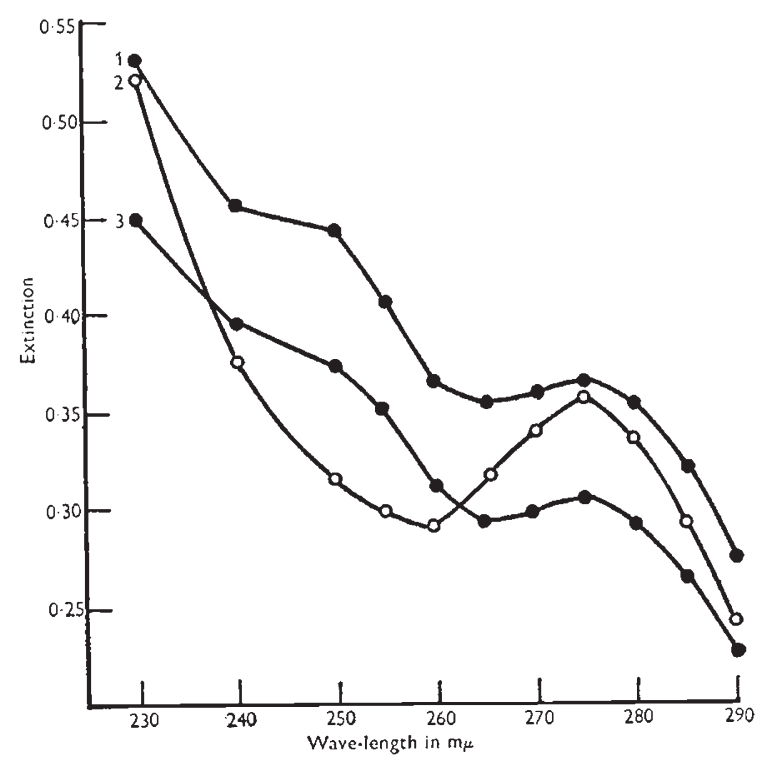

FIG. I.-Light-absorption curves of the AEA extracts of the heads of the mutants prune, raspberry and raspberry ${ }^{2}$. I, ras; $2, p_{n} ; 3$, ras $^{2}$.

\section{DISCUSSION}

The study of multiple alles affecting eye-colour in Drosophila yields data relevant to the study of genic action and gene mutation, additional to that obtained in the study of the multiple alleles of the white locus (Nolte, I959).

(I) Excepting in the raspberry alleles, all the alleles in the different series produce the normal type of red and brown pigments. In a previous study (Nolte, I952) the spectrophotometric curve was determined for the AEA extract of ras $^{2}$ eyes, but only in the region of visible light in which region the curve seems typical of the red pigment. However, correlated with the exceptional reddish-violet colour of the granule masses in the secondary, basal and post-retinal regions of both alleles (Nolte, I950) there appears a modification in ultra-violet 
absorption with a valley at $265 \mathrm{~m} \mu$ instead of at $260 \mathrm{~m} \mu$ and a peak at the usual $275 \mathrm{~m} \mu$. The rise in absorption at this pcak is flattened in comparison with other mutants, and the drop in absorption for the range $240-260 \mathrm{~m} \mu$ is different to that of the normal red pigment curve. To some extent these histological and spectrophotometric data indicate the presence of a modified constituent in the red chromophore group. In the allele $\operatorname{ras}^{3}$ no such modification is evident.

\section{TABLE}

Relative amounts of red and brown pigments in the eyes of the series of mulliple alleles

\begin{tabular}{|c|c|c|}
\hline Strain & Red pigment & Brown pigment \\
\hline $\begin{array}{l}\text { Canton-S+ } \\
s t \\
s t^{s p} \\
v \\
v^{36 f} \\
c n \\
c n^{35 / c} \\
b w \\
b w^{2 b} \\
b w^{D} \\
b w^{4} \\
p \\
p^{p} \\
c a r \\
c a r^{2} \\
g \\
g^{2} \\
g^{3} \\
g^{4} \\
r a s \\
\operatorname{ras}^{2} \\
\operatorname{ras}^{3} \\
\operatorname{ras}^{2} \text { ras }^{2} \\
\operatorname{ras}^{2} / \text { ras }^{3} \\
\text { pn } \\
\text { pn }^{2}\end{array}$ & 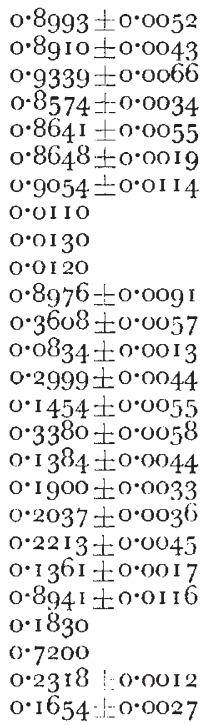 & 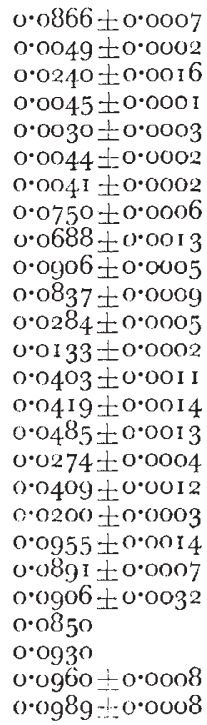 \\
\hline
\end{tabular}

(2) The quantitative data of the table include rcsults obtained in previous investigations for various members of the different series of alleles (Nolte, I 954, I955); for purposes of comparison the pigment content of the Canton-S wild-type strain is included. Two facts are to be kept in mind for the estimation of the significance of quantitative differences. First, the various strains are not equal in sizc, and size differences will naturally affect the pigment content differences. Secondly, the strains are not isogenic for any scries of genes which may affect the total amounts of pigment. Taking size differences into consideration the following are significant quantitative pigment differences.

The allele $s t^{s p}$ produces somcwhat more red pigment and about five times more AMA soluble material than does st. In the brown allcles there is a significant increase in brown pigment in the series 
$b w^{2 b} \rightarrow b w \rightarrow b w^{4} \rightarrow b w^{D}$. The rate of increase in the series is arithmetic and by nearly equal amounts for each step; $b w^{4}$, however, has an amount of red pigment equal to that of the wild-type. The allele $p$ produces about four times the amount of red pigment and about twice the amount of brown pigment that are produced by $p^{p}$. As already shown in a previous study (Nolte, I952) car compared with $c^{2}{ }^{2}$ produces about twice the amount of red pigment but an equal amount of brown pigment.

In the garnet series quantitative relations occur which are similar to those determined for the alleles of the white locus (Nolte, r959). For this series it is likewise postulated that not all members have been recognised. If an allele of garnet $\left(g^{x}\right)$ be assumed to contain the relative amounts of about 0.25 of red pigment and $0 \cdot 034$ of brown pigment, then there is a geometric rise in red pigment content in the series $g^{2} \rightarrow g^{3}, g^{4} \rightarrow g^{x} \rightarrow g$, the amount of increase bcing by a factor of about $1 \cdot 35$ for each step. The brown pigment would then show an arithmetic increase in content in the series $g^{4} \rightarrow g^{2} \rightarrow g^{x} \rightarrow g^{3} \rightarrow g$, the amount of increase for each step being about one-third of the amount present in the lowest member. These increases are equivalent to the rates of increase of the two pigments in the allele $w^{b l}$ for a drop in temperature of $\mathrm{I}^{\circ} \mathrm{C}$. (Nolte, I959). The eye colour of this presumed allele would probably resemble that of the mutant car (Nolte, I950).

There is a lesser degrce of disarrangement of the secondary pignent region in ras than in ras $^{2}$ but a greater amount of pigment in the eyes. In ras the brown pigment occurs in a relatively greater amount than in the wild-type. The allele ras $^{3}$ does not appear to affect the pigment content in the female, but taking into account the differences in eye size between the sexes, it seems from the data of the few determinations made for males that the eyes of the latter have a more or less equivalent amount of brown pigment but about one-half the amount of red pigment found in the eyes of females. In combinations between these alleles there exists an additive effect for the red pigment, but not for the brown pigment.

In the prune series the allele $p n$ produces about one-half more red pigment than $p n^{2}$ but the amounts of brown pigment are about equal; both alleles produce significantly more brown pigment than does the wild-type.

(3) The known and presumed functions of the different loci to which these multiple alleles belong have been discussed in previous studies (Nolte, I952, I 954, I 955). The scarlet locus has been postulated to act at the level of formation of brown chromophore from chromogen and substrate, this process being blocked by st. The allele $s t^{s p}$, therefore, blocks this reaction to a lesser extent; the fact that this allele produces more red pigment than does the wild type may be the result of more substrate being available for the red pigment chain of reactions. The vermilion and cinnabar loci act during the production of brown 
chromogen from tryptophane. The differences in phenotype and pigment content between $v$ and $v^{36 f}$ and between $c n$ and $c n^{35 k}$ are so small that it seems possible that these are not pairs of alleles but the same allele in each case in a different genotypic background. If the function of the brown locus is assumed to be the combination of red chromogen with substrate to form the red chromophore group, the alleles at this locus evidently block this reaction, excepting in the case of bret. However, in a single determination the combination $b w w^{4} / b w$ was found to produce the relative amounts of $0 \cdot 7102$ of red pigment and $0 \cdot 105^{\circ}$ of brown pigment, indicating that $b w^{4}$ has an action at the level of the threshold value. The production of the brown chromophore group is also affected by the alleles $b w^{4}, b w$ and $b w^{2 b}$, the decrease in content being in an arithmetic series in that order. This secondary effect of the mutants at this locus may be the result of a disturbance of the balance of reactions leading to the production of chromophore groups in the two chains.

The functions of the loci of pink, carnation and garnet have been assumed to be the directing of the specificities of enzymes utilised during the histolytic and synthetic processes of protein metabolism during metamorphosis. A product formed during these reactions is probably utilised in the chain lcading to the common substrate for the differentiating action of the white locus. The two alleles $p$ and $p^{p}$ are hypomorphic in their action, affecting the content of both pigments, $p^{p}$ slowing down the production of the red pigment to a relatively greater extent than that of the brown, as compared with $p$. A secondary effect of mutation at this locus is a disturbance of normal pigment granule formation. In the carnation and garnet loci we again find that the multiple alleles affect the production of the red pigment to a greater extent than that of the brown. In garnet the geometric rate of incrcase of red pigment in the alleles and the arithmetic rate of increase of the brown pigment are very similar to those found for the alleles of the white locus (Nolte, 1959). The latter locus acts at the end of the reaction chain on a substance provided, amongst others, by the action of the garnet and carnation loci; at both loci the alleles show qualitative differences, when arranged in series, in regard to the quantitative cffect on the two pigments.

The function of the locus of raspberry has been suggested to be that of synthesis of cytoplasmic proteins for pigment cell differentiation; the mutant alleles cause a decrease in number and a disturbance in the orientation of the basal pigment cells and this results in a disorganization of the secondary pigment region, more so in $r^{2} s^{2}$ than ras. Correlated with this disruption is the decrease in red pigment content and the slight modification of part of the red chromophore group, a pointer to the possibility that a substancc (protein) used both in cell and chromophore production is modified. The significant increase in brown pigment content in ras as compared with the wildtype might be a secondary effect of the disturbed balance in the 
processes leading to pigment deposition. In the case of $\mathrm{ras}^{3}$ the mutation seems to have reduced the efficiency of the locus to the level of the threshold of activity. The locus of prune has also been shown to

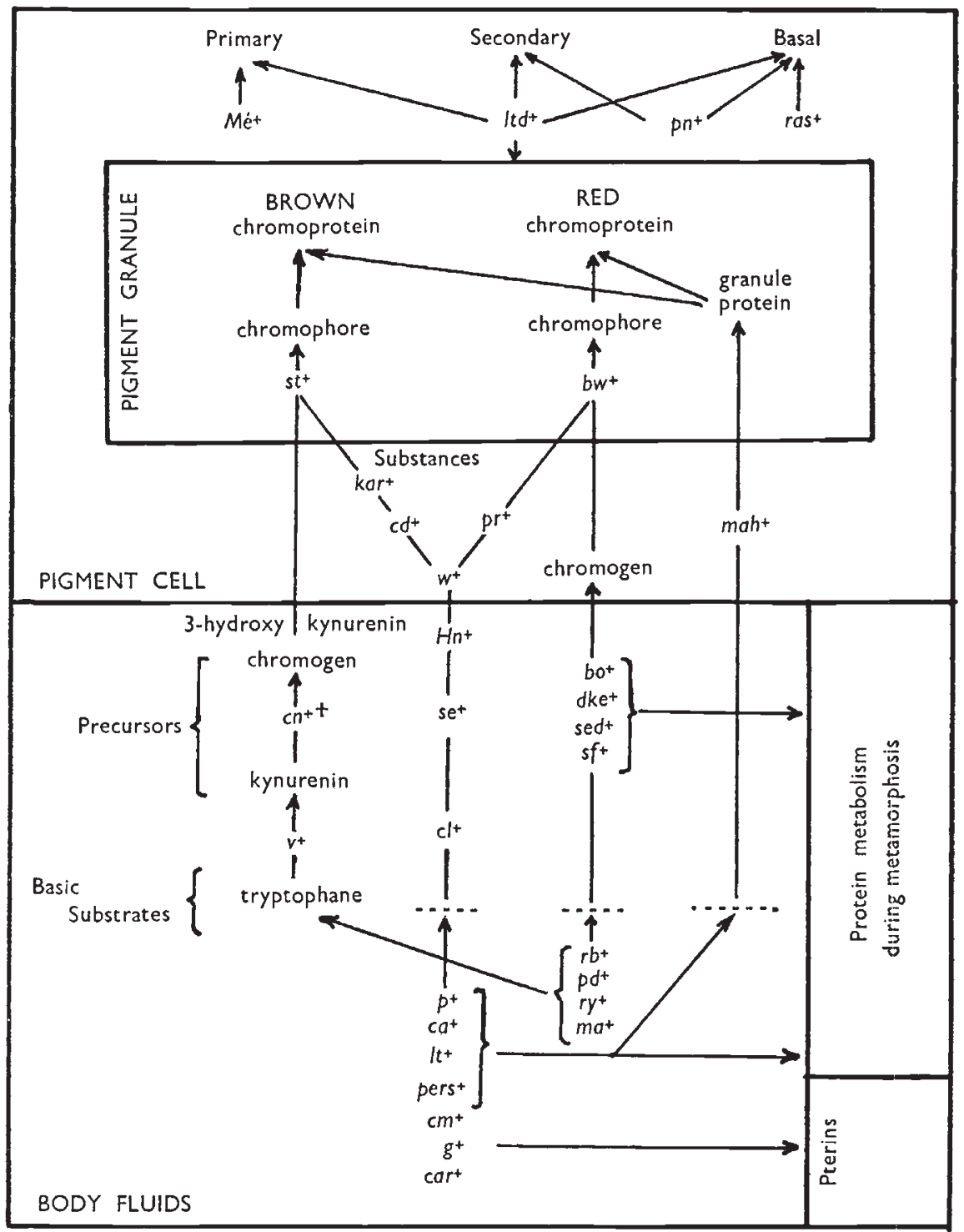

FIG. 2.-Diagrammatic representation of the known and postulated functions of the main eye-colour genes in $D$. melanogaster.

affect the differentiation of the pigment cell regions. The allele $p n^{2}$ shows a greater amount of disorganization of the secondary pigment cell region than does the allele $p n$, and a correlated greater decrease in red pigment content but a relatively higher brown pigment content; the amount of brown pigment is significantly greater in both 
alleles than in wild-type. These quantitative effects may result secondarily from disturbances in the methods of deposition of the two pigments.

The discussion on the known and presumed functions of the eyecolour genes that have been investigated in this study and in others (Nolte, 1952, 1954, 1955) may be clarified by a diagrammatic representation (fig. 2).

\section{SUMMARY}

The seventh group of eye-colour mutants of Drosophila melanogaster to be studied histologically and spectrophotometrically comprises the scries of multiple alleles at the loci of scarlet, vcrmilion, cinnabar, brown, pink, carnation, garnct, raspberry and prune.

I. Histologically the multiple alleles of a scries produce similar specific effects, e.g. in the general colour of the four pigment regions, in the type of granules produced and in the orientation of the pigment cells. Thus $p$ and $p^{p}$ produce some granules larger than normal in the secondary pigment cells; car and $c a r^{2}$ have very small basal pigment masses; the alleles $g^{2}, g^{3}$ and $g^{4}$ appear to have brown pigment only in the primary cells; the allcles ras and $\mathrm{ras}^{2}$ show a decrease in the number of basal cclls and a clumping of the pigment masses in the secondary cells; in $p n$ and $p n^{2}$ a similar picture of disorganization of the sccondary cells appears.

2. All the mutants produce the normal types of red and brown eyc pigments excepting ras and ras $^{2}$ for which the red pigment cxtracts shows a modificd photometric curve in the ultra-violet region, indicating a modification in the red chromophore group.

3. The quantitative relations of the two pigments vary for the different series of alleles. In the brown series the brown pigment shows an arithmetic increase in the four alleles; in three alleles the red pigment is absent but in bre the normal amount is present. The two alleles in each of the pink and carnation series show a greatcr difference in the red than in the brown pigment content. In the garnet series the existence of a fifth member $\left(g^{x}\right)$ is postulated and if this is so the red pigment shows a geometric rate of increase while the brown pigment content rises arithmetically for a different order of the alleles. In the raspberry and prune series the disarrangement in the pigment cell regions is correlated with a decrease in the red pigment content but an increase in brown pigment. In as $^{3}$ the activity of the locus has apparently been lowered to the threshold value (lower in the hemizygous male).

4. The known and presumed functions of these loci arc discussed.

\section{REFERENCES}

BRIDGeS, C. B., AND BREHME, K. S. I944. The mutants of Drosophila melanogaster. Carneg. Instn. Publ., 552, I-257.

NoltF, D. J. I950. The eye-pigmentary system of Drosophila: the pigment cells. F. Genet., 50, 79-99. 
NOLTE, D. J. I952. The eye-pigmentary system of Drosophila. III. The action of eye-colour genes. 7. Genet., 51, 1 $42-186$.

NOLTE, D. J. I954. The eye-pigmentary system of Drosophila. IV. The pigments of the vermilion group of mutants. 7. Genet., 52, i I I-1 26.

NOLTE, D. J. I954. The eye-pigmentary system of Drosophila. V. The pigments of the light and dark groups of mutants. F. Genet., 52, I 27 -1 39.

NOLTE, D. J. r955. The eye-pigmentary system of Drosophila. VI. The pigments of the ruby and red groups of mutants. 7. Genet., 53, I-1o.

NOLTE, D. J. I959. The eye-pigmentary system of Drosophila. VII. The white locus. Heredity, 13, $219-231$. 